\title{
Eventos Hidrológicos Extremos na Cidade de Salvador-BA: Análise Espacial de Ocorrências de Alagamentos
}

Tayná Freitas Brandão; Rosângela Leal Santos; Liamara Carelli, carelli@uefs.br

RESUMO

A ação do homem no espaço faz com que as condições do sistema natural sejam alteradas, o que promove novos processos através de um sistema de retroalimentação, já que a natureza não é passiva às intervenções humanas. $\mathrm{O}$ espaço urbano representa uma das maiores expressões das transformações provocadas pela sociedade na paisagem natural e essa natureza humanizada, vinculada à impermeabilização do solo em associação à ocupação desordenada e à retirada da cobertura vegetal, entre outros fatores, tende a modificar os processos naturais, afetando de forma direta os habitantes. Os alagamentos e inundações são sérios problemas nas cidades brasileiras, já que o solo impermeável diminui ou impossibilita a infiltração das águas pluviais causando o aumento do escoamento superficial que, somado à drenagem ineficiente provocam transtornos em diversos setores da vida urbana. Considerando a importância social deste tema e através da modelagem de dados este trabalho tem como objetivo a análise das áreas afetadas por eventos hidrológicos extremos na cidade de Salvador a partir da espacialização dos dados de precipitação de oito estações pluviométricas, dados de distribuição pontual das ocorrências mensais de alagamentos e a delimitação de áreas de risco e áreas de concentração de ocorrências de alagamentos através da análise de densidade de pontos de Kernel. A integração dessas informações permitirá subsidiar a tomada de decisão em relação aos pontos críticos de drenagem da cidade, auxiliando a atuação dos órgãos públicos e possibilitando a substituição do atual modelo de reparação e recuperação de danos para um modelo de prevenção.

Palavras chave: alagamentos, precipitação, espaço urbano.

\section{Events Hydrological Extremes in Salvador-BA: Spatial Analysis Flooding Occurrences}

\begin{abstract}
The actions of humans impact the environment and cause a natural system condition to change, which promotes new processes through a feedback system, since nature is not immune to human intervention. Urban spaces are one of the greatest expressions of the changes brought about by societies in the natural landscape. Human intervention via populating is linked to soil sealing in combination with disorderly occupation and the removal of vegetation cover, among other factors and tends to modify the natural processes, which directly affect the inhabitants. Waterlogging and floods are serious problems in Brazilian cities since the impermeable soil decreases or prevents the infiltration of rainwater causing increased runoff which, added to inefficient drainage cause disorders in various sectors of urban life. Considering the social importance of this issue and through data modeling this work aims to analyze the areas affected by extreme hydrological events in the city of Salvador from the spatial distribution of precipitation data from eight rainfall stations, using timely data records of distribution of monthly occurrences of flooding and demarcation of risk areas and areas of concentration of flooding occurrences through the Kernel points density analysis. The integration of this information will support the decision making on critical points of city drainage, aiding the work of public agencies and allowing the replacement of the current model of repair and recovery of damage to a prevention model.
\end{abstract}

Keywords: flooding, rainfall, urban space.

Recibido el 30 de mayo de 2016; aceptado el 30 de junio de 2016.

Laboratório de Geotecnologias, Universidade Estadual de Feira de Santana, Av. Transnordestina, s/n - Novo Horizonte, Feira de Santana - Brasil, 44036-900. 


\section{INTRODUÇÃO}

A maior parte da população do planeta concentra-se hoje em áreas urbanas, fato que ocorre especialmente nos países mais pobres, cuja migração da população rural para os centros urbanos foi um fenômeno muito intenso. No Brasil, o processo de urbanização acelerado ocorrido após a década de 1960, com redução de investimentos na década de 80 , resultou em aglomerados urbanos com taxa populacional acima de $80 \%$ associado à infraestrutura precária (TUCCI 2002).

Essa concentração urbana tem trazido reflexos negativos que podem ser percebidos através da degradação ambiental e das condições de vida da população, uma vez que tais impactos afetam a integridade urbana.

Nessa perspectiva, o crescimento da urbanização pode ser apontado como causa da intensa modificação no uso do solo, promovendo a redução da infiltração e o consequente aumento no volume de escoamento superficial. Esse processo traz como consequência alterações no ciclo hidrológico, ocasionando inundações e alagamentos que atingem a população de forma intensa e provocando prejuízos sociais e econômicos (BECKER 2006).

NETO (1998; 2008) ressalta, ainda, o surgimento de alterações na dinâmica atmosférica local, com rebatimentos no clima urbano, cuja origem está relacionada às modificações impostas à paisagem natural, especialmente no que se refere às atividades industriais, alta concentração de construções de alvenaria com utilização de cimento e substituição de áreas verdes por áreas construídas.

Todavia, os impactos causados por tais fenômenos não dependem unicamente de condições atmosféricas e se tornam riscos quando a sociedade não apresenta capacidade de evitar seus efeitos negativos (GONÇALVES 2003). Assim, deve-se levar em consideração tanto questões climáticas, englobando análises de aspectos físicos dos fenômenos atmosféricos, como sociais, levando-se em conta características de ocupação do solo, planejamento e dinâmica da sociedade atingida.

Apesar de todo o avanço da ciência e da tecnologia, que possibilitou ao ser humano conhecimento parcial dos processos naturais, o homem ainda se percebe vulnerável diante de eventos naturais extremos, pois este conhecimento não pressupõe controle dos processos supracitados. A questão dos desastres naturais, que englobam catástrofes de natureza hidrometeorológica (como inundações), geológica (como terremotos), biológica (como epidemias) e tecnológica, vem sendo alvo de análises e pesquisas (MONTEIRO 1991) uma vez que suas consequências são cada vez mais catastróficas e responsável por imensos prejuízos.

A previsão de áreas atingidas por alagamentos é fortemente dependente da topografia, ocupação e mudanças climáticas e se configura como um processo dinâmico e complexo, tanto no que se refere ao contexto espacial quanto temporal.

De acordo com as análises de GRILLO \& BRINO (1994), os alagamentos ocorrem geralmente, em áreas planas ou com depressões e fundos de vales, com o escoamento superficial comprometido pela topografia e falta ou insuficiência de um sistema pluvial no ambiente urbano.

SAYDELLES (2005) citando Mayer (1975) define o sítio urbano como a área ocupada pela cidade. Com relação aos aspectos que devem ser avaliados no estudo do sítio urbano, o autor destaca o relevo, a inclinação e a configuração das áreas cobertas ou não por água, a vulnerabilidade a terremotos, deslizamentos de terra, 
inundações e outras condições catastróficas e a capacidade de sustentação e sobrecarga, referente ao substrato rochoso, à drenagem e às condições microclimáticas.

O crescimento desordenado e acelerado da cidade de Salvador (BA), em conjunto com a falta de planejamento urbano e ambiental, propiciou o surgimento e ocupação de áreas vulneráveis à ocorrência de riscos $\mathrm{e}$ desastres naturais e sociais.

Os estudos de ecologia urbana sofreram profundas mudanças a partir da década de 70, dada a emergência de uma consciência ambientalista e ecológica, e nessa perspectiva, o debate acerca de cidades sustentáveis vem ganhando espaço, principalmente a partir da década de 80 , como afirma MENDONÇA (2004), com a pretensão de estabelecer condições de vida para o homem urbano, uma vez que sua condição biológica exige que o mesmo conviva com um ambiente não deteriorado. MENDONÇA (2004) destaca que os fluxos de matéria e energia naturais e/ou produtos da ação humana interagem no contexto urbano, formando a materialidade urbana, e é dessa complexa interação que surgem os problemas ambientais.

Foi a partir da tomada de consciência do fato urbano que o homem passou a perceber que a atmosfera sobre a cidade era sensivelmente diferente daquela do campo (MONTEIRO 1976). Embora a urbanização de certos países europeus remontem ao século XVII, foi somente no século $\mathrm{XX}$, que geógrafos e meteorologistas europeus e americanos passaram a dar atenção à atmosfera sobre as cidades e/ou climas urbanos.

A urbanização provoca modificações nos elementos climáticos (Tabela 1) como afirma AYOADE (1986: 300) "O maior impacto do homem sobre o clima acontece nas áreas urbanas. $\mathrm{O}$ homem tem exercido um impacto tão grande nessas áreas que o clima urbano é bastante distinto, por suas características, do clima das áreas rurais circundantes".

Tabela 1. InfluênCia da uRbanizaÇão SObre os Elementos Climáticos.

TABle 1. Influence OF DEVElopment about the Climate Elements.

\begin{tabular}{ll} 
Elementos & Comparação com a Zona Rural \\
\hline Aquecimento de graus-dia & $10 \%$ menor \\
\hline Umidade Relativa do Ar & \multicolumn{2}{l}{$6 \%$ menor } \\
\hline Média anual & $2 \%$ menor \\
\hline Inverno & $8 \%$ menor \\
\hline Verão & \\
\hline Velocidade do Vento & 20 a $30 \%$ menor \\
\hline Média anual & 10 a $20 \%$ menor \\
\hline Movimentos extremos & 5 a $20 \%$ maior \\
\hline Calmarias &
\end{tabular}

Fonte: AYOADE (1986). Modificado pelos autores.

Source: AYOADE (1986). Modified by the authors. 
A cidade gera um clima próprio (clima urbano), resultante da interferência de todos os fatores que se processam sobre a camada de limite urbano e que agem no sentido de alterar o clima em escala local (MONTEIRO 1976; MONTEIRO \& MENDONÇA 2003). Seus efeitos mais diretos são percebidos pela população através de manifestações ligadas ao conforto térmico, à qualidade do ar, aos impactos pluviais e outras manifestações capazes de desorganizar a vida da cidade e deteriorar a qualidade de vida de seus habitantes.

A análise rítmica, importante instrumento aos estudos de clima urbano, foi introduzida por MONTEIRO (1971) com base no conceito de clima DE SORRE, que em 1951 definiu ritmo como a sucessão de estados atmosféricos de determinado lugar. Considerada um novo paradigma, a análise rítmica foi sistematizada por MONTEIRO (1971) e seus seguidores e tem como ferramenta as respostas locais das variações diárias e horárias dos elementos do clima, através de medições em superfície (estações e postos meteorológicos), complementadas pelas cartas sinóticas do tempo e imagens de satélites meteorológicos (ZAVATINI 2002).

A partir da análise dessas informações, podese verificar o ritmo da sucessão dos tipos de tempo, ou seja, a dinâmica atmosférica. Assim, o ritmo climático só poderá ser compreendido através da representação concomitante dos elementos fundamentais do clima em unidades de tempo cronológico pelo menos diárias compatíveis com a representação da circulação atmosférica regional, geradora dos estados atmosféricos que se sucedem e constituem o fundamento do ritmo (MONTEIRO 1971).

A abordagem geográfica é alcançada, de acordo com MONTEIRO (1969), a partir da análise dos tipos de tempo em sequência contínua, seja de forma comparativa entre anos considerados padrões representativos da circulação atmosférica de determinado lugar, nas variações sazonais, ou até mesmo pela análise de um fenômeno local.

A precipitação pode variar em sua distribuição sazonal, diária e quanto à intensidade (AYOADE 1986), o que faz com que seja considerada como uma das variáveis climáticas de maior influência na qualidade do meio físico-natural, refletindo, direta ou indiretamente nas atividades humanas (SARTORI 1993).

AYOADE (1986), a intensidade da precipitação é sua quantidade dividida pela duração, em horas ou minutos, tendo a precipitação convectiva geralmente maior intensidade do que a ciclônica ou frontal. $\mathrm{O}$ autor propõe o índice de intensidade média, onde um dia é considerado chuvoso quando tem pelo menos $0,25 \mathrm{~mm}$ de precipitação.

Os eventos naturais extremos que mais repercutem nas atividades humanas no Brasil são os eventos climáticos (BRANDÃO 2001; MARENGO 2009; IPEA 2011). Estes são causados por fatores naturais, associados à disritmias no sistema meteorológico, embora venham sofrendo a atuação do homem, que contribui para sua maior frequência, intensidade e expansão areolar.

Assim, eventos pluviométricos excepcionais fazem parte da dinâmica ambiental, porém podem desencadear impactos ao ambiente físico, biológico e às atividades humanas, e dessa forma, a caracterização do comportamento das precipitações em determinada área é importante na análise de susceptibilidade a enchentes (HERRMANN 2001; JARDIM 2012).

De acordo com MONTEIRO (1969), essa caracterização não deve levar em conta apenas médias anuais ou mensais, mas também a análise episódica dos índices pluviais extremos. A partir desses dados define-se os anos padrões secos ou chuvosos e deve-se definir, também, o sistema atmosférico responsável por situações extremas de precipitação, levando-se em 
conta, ainda, as características naturais do sítio urbano, como a presença de planícies de inundação, por exemplo.

TUCCI (2002) e ZANELLA (2007) sugere que o aumento da temperatura nas cidades cria condições de movimentação de ar ascendente, o que pode gerar o aumento da precipitação. Essas precipitações, geralmente intensas e de curta duração, contribuem para agravar as enchentes urbanas.

\section{GRILLO \& BRINO (1994) e GONÇALVES}

(2003) ao consultarem a literatura referente à variação da precipitação de áreas urbanas em relação às rurais, verificaram que as pesquisas apontam para o aumento do volume da precipitação nas áreas urbanas, aumento este relacionado à direção do vento, ampliação da ocorrência de tempestades, maior freqüência das precipitações com volumes menores, aumento de dias com tempestades de granizo e diminuição da precipitação de neve nos centros das cidades.

Deve-se levar em conta, no entanto, que a natureza da alteração não é comum a todas as cidades, pois cada área urbana apresenta características próprias devido à sua localização geográfica, topografia, estrutura e condições climáticas (GRILLO \& BRINO 1994).

Apesar da dificuldade em estabelecer uma correlação entre urbanização e precipitação, ATKISON (1975) afirma que a área de maior atividade de uma tempestade se dá sobre a área urbanizada e SELLERS \& ROBINSON (1986) menciona que o aumento da rugosidade da superfície urbana força o ar a elevar-se na troposfera favorecendo a nebulosidade, aumentando consequentemente as taxas de precipitação. O índice de poluição segundo LANDSBERG (1981) constitui também um importante fator no aumento das precipitações, por gerar um maior número de núcleos de condensação e por sua vez, influenciar na formação do tamanho das gotas.

Os impactos causados pela urbanização em um ambiente natural podem ser constatados a partir da análise do ciclo hidrológico. Qualquer meio natural tem sua forma determinada principalmente pela ação das águas entre outros condicionantes físicos, sendo que as águas pluviais são dissipadas através da evapotranspiração, infiltração e escoamento superficial.

Com o crescimento dos centros urbanos, todos estes processos são reduzidos drasticamente, o que faz aumentar o escoamento, encurtando o seu tempo de concentração, causando graves reflexos nos cursos de drenagem natural, bem como provocando erosão, assoreamento e enchentes (BARBOSA 2006).

Fazendo uma análise das principais catástrofes naturais ocorridas no mundo durante o período de 1988 a 1998, Lobster (1999) citado em CÂNDIDO (2007) aponta que as inundações correspondem a $1 / 3$ de todos os eventos registrados. Além disso, os cenários projetados enfatizam que a conjunção entre a atmosfera mais instável e aquecida, a ocupação generalizada e a degradação de áreas naturalmente passíveis de inundações levaram a um aumento desses eventos, com conseqüências dramáticas em escala global. Contudo, os efeitos cristalizam-se no nível local, justificando estudos específicos para os municípios afetados.

A realidade brasileira, no contexto dos desastres ambientais, pode ser caracterizada pela freqüência dos desastres naturais cíclicos, especialmente pelas inundações em todo o país, pela seca na região Nordeste e por um crescente aumento dos desastres antropogênicos devido ao crescimento urbano desordenado, às migrações internas $\mathrm{e}$ ao fenômeno da urbanização acelerada sem a disponibilidade dos serviços essenciais relativos às infraestruturas urbanísticas, de saneamento, entre outros (BRASIL 2007). 
CHRISTOFIDIS (2001) explica essa situação afirmando que o caráter cíclico das cheias urbanas em associação às dificuldades enfrentadas pelas administrações municipais, especialmente a falta de conhecimento geral do regime de chuvas, leva à interrupção e ao abandono de atividades humanas durante o período crítico, o que agrava os problemas a cada ano.
Diante deste cenário, é de se esperar que as inundações no território brasileiro tendam a ser mais frequentes e prejudiciais ano a ano, comprometendo assim o desenvolvimento nacional (CUNHA 2007), uma vez que os eventos hidrológicos se destacam na causa de desastres brasileiros reconhecidos como situação de emergência e estado de calamidade pública, no período de 2003 a 2006 (Fig. 1).

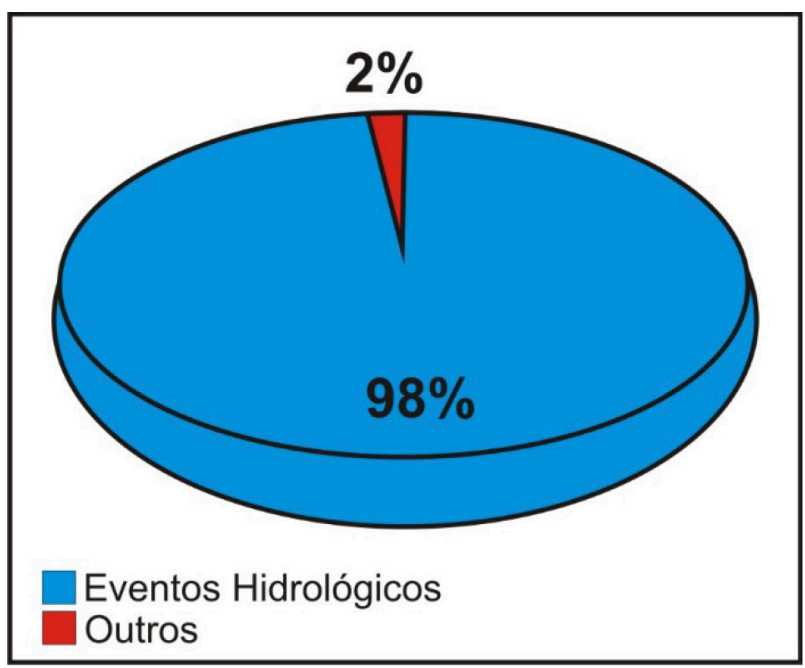

Fig. 1. Causas dos desastres brasileiros no período de 2003 a 2006 Fonte: Informativo Defesa civil segundo CUNHA (2007).

Fig. 1. Causes of Brazilian disasters from 2003 to 2006 Source: Defesa Civil Informative according CUNHA (2007).

Situada no litoral leste da região Nordeste do Brasil, a capital baiana é uma das cidades brasileiras de maior pluviosidade anual, $2.099 \mathrm{~mm}$, dos quais $52,5 \%(1.101,4$ mm) são registrados no período de Abril a Julho (DNMET, 1992) e, a depender da intensidade, duração e frequência das chuvas, esse quadrimestre também se destaca pelo número de eventos intensos e pela quantidade e gravidade dos efeitos adversos que provocam à cidade.

O município de Salvador apresenta características geoecológicas que definem uma paisagem intertropical resultante das interrelações entre a estrutura geológica e a dinâmica externa comandada pelo clima. Sua compartimentação morfológica está relacionada ao embasamento cristalino, constituído de rochas de alto grau de metamorfismo-granulitos e metabasitos de idade Pré-Cambriana, localmente cortadas por diques e veios de pegmatitos, aplitos e diabásios, que constituem o bordo oriental da bacia sedimentar do Recôncavo ALMEIDA (2002).

Suas feições estruturais, relacionadas à tectônica que deu origem à Bacia do Recôncavo, caracterizam-se pela grande 
falha de Salvador, cuja escarpa abrupta separa a cidade em dois planos altimétricos, a cidade alta e a Cidade Baixa, e por falhamentos secundários que favoreceram e guiaram a instalação e a direção da rede de drenagem local (NETO 2006).

De acordo com um estudo realizado pelo IBGE (2000), pode-se verificar que somente 264 dos 417 municípios da Bahia possuem serviço de drenagem urbana, o que representa $63,61 \%$ dos municípios baianos. Neste contexto, o elevado índice pluviométrico local, que alcança uma média anual de $1.826 \mathrm{~mm} /$ ano no posto pluviométrico de Ilha Amarela no período de 2002 a 2008, demonstra que poucas capitais do país apresentam índices tão altos como Salvador, sendo que $67 \%$ do total precipitado no ano ocorre nos meses do outono/inverno.

NETO (2006) afirma que tal fato caracteriza que neste período a cidade convive com longos períodos de chuvas insistentes, contínuas, de intensidades fracas, moderadas e/ou altas, que gradativamente vão saturando o terreno e proporcionando condições extremamente favoráveis ao escoamento superficial, pois reduz significativamente a capacidade de infiltração da água no solo.

A topografia, predominantemente acidentada nos morros que compõem a paisagem natural, associada ao tipo de solo e ao elevado índice de ocupação das encostas, aumentam sensivelmente a impermeabilização do solo local. Consequentemente, o processo de infiltração das águas pluviais no solo fica prejudicado, possibilitando uma intensidade de escoamento muito maior e rápida aos eventos pluviais intensos. Estes parâmetros interferem diretamente na redução dos tempos de concentração, aumentando a possibilidade de enxurradas e configurando simultaneamente inúmeras condições favoráveis à formação de enchentes.
As áreas onde são mais comumente registradas ocorrências de inundações e/ou alagamentos em Salvador correspondem, segundo GONÇALVES (2003), às avenidas de vale, às áreas pantanosas e/ou submetidas a aterros, aos loteamentos públicos ou privados (sem dimensionamento adequado da infraestrutura de drenagem) e às planícies aluviais ocupadas indevidamente.

Com base em tudo o que foi apresentado, as preocupações ambientais relacionadas à drenagem e aos alagamentos urbanos têm sido um dos desafios dos planejadores e administradores da esfera municipal, que para atender às novas demandas criadas, necessita de um incremento na eficiência através de novas abordagens e do uso métodos não convencionais de integração e análise.

Assim, fica evidente a necessidade de aprofundamento no que se refere à distribuição rítmica da pluviosidade em Salvador no que se refere tanto à quantidade quanto à gravidade dos transtornos causados quando da ocorrência de eventos de chuva intensa, com vistas a analisar, em uma perspectiva espacial, a relação existente entre a concentração e distribuição de precipitação pluviométrica e os pontos de alagamentos da cidade.

\section{MATERIAIS E MÉTODOS}

A delimitação da pesquisa conteve três recortes do objeto de estudo: (1) Temático, o qual restringiu-se aos alagamentos caracterizados pela defesa civil como situação de emergência e de estado de calamidade pública; (2) Temporal, que compreende o período de 2006 a 2009 e (3) Geográfico, a cidade de Salvador (BA), área de atuação da defesa civil.

Assim, a etapa inicial do trabalho consistiu na coleta de informações junto à comissão de Defesa Civil de Salvador com vistas a consultar o histórico de ocorrências de 
alagamentos na cidade. Foram obtidos dados de ocorrências do período de 2006 a 2009. Esses dados são cadastrados a partir de solicitações feitas pela população, podendo existir casos que não foram registrados.

$\mathrm{Na}$ fase posterior, foram coletados os dados pluviométricos de oito estações climatológicas de Salvador junto ao Instituto de Gestão de Águas e Clima (INGÁ), órgão vinculado ao Governo do Estado da Bahia.
Foram utilizadas as séries pluviométricas de postos pluviométricos distribuídos pela cidade de Salvador, pré-definidas com as seguintes localizações: CIA do Aterro Metropolitano de Salvador, Aterro Canabrava, INGÁ em Itapuã, Estação climatológica do INMET de Ondina, $19^{\circ}$ Batalhão no Cabula, Ilha amarela, Monte Serrat, Base Naval de Aratu (Fig. 2).

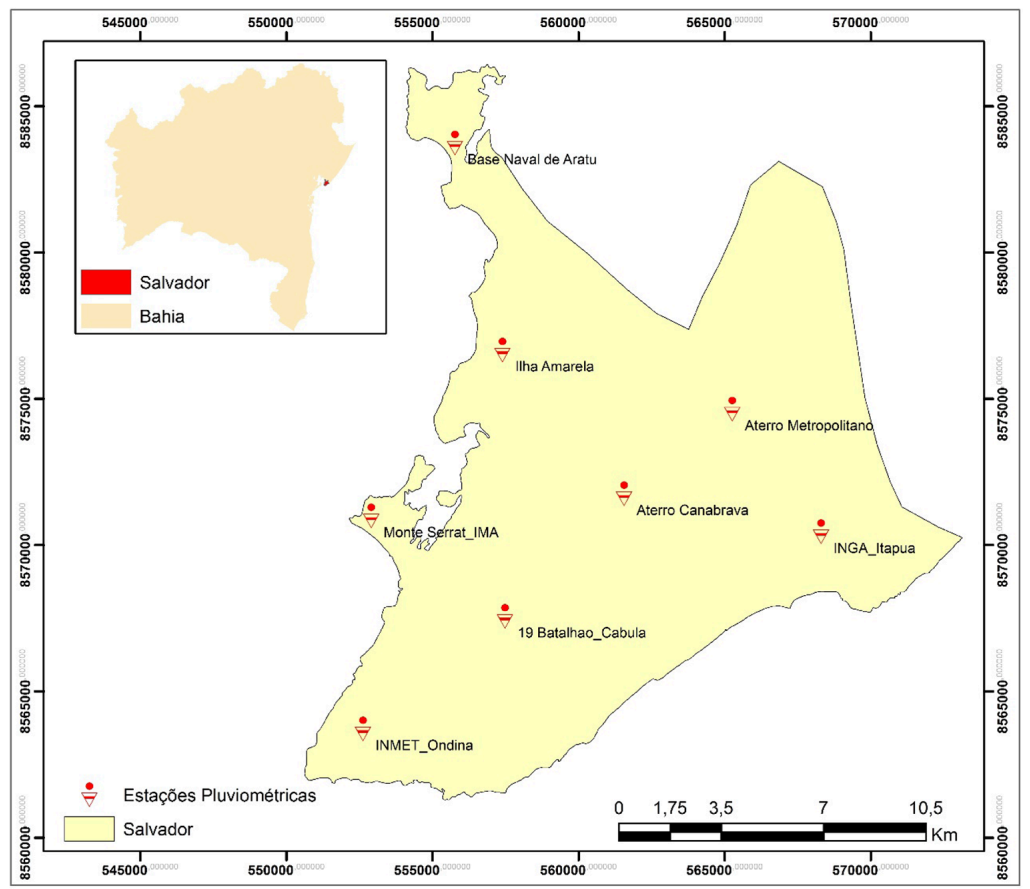

Fig. 2. Localização dos postos pluviométricos distribuídos na cidade de Salvador/BA.

Fig. 2. Location of rainfall stations distributed in the city of Salvador / BA.

Escolheu-se o quadriênio de 2006 a 2009 , por este ser o período com disponibilidade de dados pluviométricos nos oito postos distribuídos pela cidade de Salvador, o que possibilita a interrelação espacial dos dados e seu posterior cruzamento com os dados de alagamentos obtidos junto à Defesa Civil neste período.

Para o mapeamento da variabilidade espacial de um determinado atributo é necessário ter um banco de dados que apresente o valor e a localização do atributo. Esse banco de dados é normalmente obtido em uma amostragem não regular de pontos dentro da área avaliada e é denominado de dados brutos. Assim, para se obter uma grade regular de pontos é necessário o uso de interpoladores para estimar pontos em locais que não foram amostrados. A interpolação dos 
dados de precipitação pluvial foi efetuada utilizando-se o programa Surfer 9.0, através do algoritmo de mínima curvatura.

A interpolação de dados é importante para eliminar o chamado efeito mosaico ou efeito xadrez presentes em geral na visualização de mapas temáticos e para chamar a atenção para as principais concentrações espaciais de determinado atributo, suavizando suas diferenças. Dessa forma, foi utilizada a interpolação por mínima curvatura para a espacialização dos dados de precipitação pluviométrica das oito estações para se obter a distribuição da precipitação na cidade.

Para a elaboração das cartas de riscos que auxiliaram na interpretação dos dados e no mapeamento das áreas mais afetadas durante o período de 2006 a 2009, utilizouse o software ArcView 3.3 para a inserção de dados de ocorrências de alagamentos no shape de Salvador, inserindo-se pontos nos locais das ocorrências através da tabela de atributos. Esta base cartográfica foi fornecida pela Secretaria de Segurança Pública da cidade de Salvador.

Com vistas a obter o mapa das áreas de risco do município do Salvador optouse pelo método de suavização de Kernel que calcula a intensidade pontual do evento e, para isso, utilizou-se o software Spring 4.3.3. O método de suavização de Kernel realiza uma contagem de todos os pontos dentro de uma região de influência, ponderando-os pela distância de cada um à localização de interesse.

Para a identificação de padrões de concentração espacial dos pontos, neste caso os alagamentos segundo o local de ocorrência, foi aplicada a técnica de Kernel, cujo estimador foi desenvolvido para obter a estimativa de probabilidade de densidade uni ou multivariada de uma determinada amostra. $\mathrm{O}$ método, não paramétrico, faz a estimativa alisada da intensidade local dos eventos sobre a área estudada, resultando em uma superfície de risco para sua ocorrência e vale ressaltar que, no contexto espacial, o fatiamento é uma técnica exploratória valiosa para a identificação de hot spots ou áreas que apresentem homogeneidade.

Assim, para a elaboração de cartogramas de densidade pelo método Kernel, foi utilizado um raio de 2.000 metros, de forma a analisar a evolução na escala espaço-temporal das localidades afetadas pelos eventos extremos na cidade de acordo com a amostra que obtivemos. Após o processamento dos cartogramas de densidade, foi realizado um fatiamento das classes para determinar os intervalos de ocorrências dos eventos: entre 1 e 5 ; de 5 a 10 ; de 10 a 15 ; de 15 a 20 ; de 20 a $25 ;$ de 25 a $30 ;$ de 30 a $35 ;$ de 35 a 40 e maiores que 40 pontos de ocorrências.

Para a modelagem de previsão foi caracterizada a variabilidade sazonal da chuva, sua correlação espacial com base nas séries pluviométricas de postos pluviométricos distribuídos pela cidade, conforme apresentado na figura 2.

Com o SIG, associado à espacialização da precipitação mensal da cidade e o relatório dos locais de ocorrência de alagamentos, foi possível conceber uma base de dados e de diagnóstico de possíveis áreas de alagamentos na cidade de Salvador (BA).

\section{RESULTADOS}

Alagamentos são frequentes em Salvador, deixando como saldo um número significativo de mortos e desabrigados, e no momento em que isto ocorre, a imprensa e órgãos governamentais voltam a atenção para o problema. Predominantemente, o processo começa nas áreas altas dos morros que compõem a paisagem natural, onde geralmente estão construídas as ruas e avenidas de cumeadas. Nestas áreas, 
cujas declividades longitudinais são altas, o que favorece as condições naturais do escoamento superficial, foi constatato que o sistema de microdrenagem, quando existe, é pouco denso e as poucas bocas de lobo existentes muitas vezes estão mal posicionadas em relação ao escoamento superficial promovido pela declividade da rua, e além disso, estão constantemente obstruídas.

Isto ocorre em diversos casos nos quais observou-se que as bocas de lobo estavam completamente obstruídas por detritos diversos e lixo carregado pela água da chuva, caracterizando-se uma condição operacional praticamente ineficaz. $\mathrm{O}$ escoamento superficial, sendo incrementado gradualmente pelas áreas contribuintes, geradas pela impermeabilização, aumenta de volume e de velocidade de fluxo buscando alternativas topográficas naturais para acessar as áreas baixas dos talvegues da macro drenagem.

\section{Breve Análise da Precipitação}

Segundo a Superintendência de Estudos Econômicos e Sociais da Bahia (2000) o clima de Salvador é caracterizado como tropical úmido a super úmido, com precipitações medias anuais de $2.099 \mathrm{~mm}$ e temperatura média anual de $25,3^{\circ} \mathrm{C}$, sendo os meses compreendidos entre Setembro e Fevereiro os menos chuvosos, com precipitações entre 111 e $132 \mathrm{~mm}$.

O trimestre mais chuvoso, representado pelos meses de Abril, Maio e Junho, apresenta uma precipitação média mensal que varia de $251 \mathrm{~mm}$ a $325 \mathrm{~mm}$. Os meses com excedente hídrico superior a 100 mm correspondem a Abril, Maio, Junho e Julho, enquanto a maior deficiência hídrica registra-se nos meses de Janeiro e Fevereiro com $8,5 \mathrm{~mm}$ e $3,9 \mathrm{~mm}$, respectivamente. Nesse contexto, as médias mensais de precipitação, considerando as oito estações analisadas para o período 2006-2009, corrobora o exposto acima (Tabela 2).

Tabela 2. MÉdia mensal de PReCiPITAÇÃo das oito estaÇões PluViométriCas.

Table 2. Monthly aVerage of rainfall station of the Eight flag station Rainfall.

\begin{tabular}{ll|l|l|l}
\multirow{2}{*}{ Mês } & $\mathbf{2 0 0 6}$ & $\mathbf{2 0 0 7}$ & $\mathbf{2 0 0 8}$ & $\mathbf{2 0 0 9}$ \\
\cline { 2 - 5 } Janeiro & 36,03 & 25,43 & 9,06 & 30,90 \\
\hline Fevereiro & 27,53 & 199,64 & 139,10 & 83,57 \\
\hline Março & 63,48 & 120,03 & 171,14 & 41,56 \\
\hline Abril & 534,31 & 149,66 & 161,39 & 383,15 \\
\hline Maio & 441,00 & 187,58 & 254,95 & 706,50 \\
\hline Junho & 419,40 & 139,14 & 187,99 & - \\
\hline Julho & 133,44 & 137,26 & 146,82 & - \\
\hline Agosto & 101,06 & 102,68 & 79,50 & - \\
\hline Setembro & 99,56 & 86,23 & 41,99 & - \\
\hline Outubro & 196,73 & 60,70 & 50,51 & - \\
\hline Novembro & 180,66 & 14,24 & 60,72 & - \\
\hline Dezembro & 14,06 & 18,77 & 101,80 & - \\
\hline
\end{tabular}

Fonte: Instituto de Gestão de Águas e Clima (2010). Source: Instituto de Gestão de Águas e Clima (2010). 
$\mathrm{O}$ número de ocorrências de alagamentos registrado pela Defesa Civil varia ao longo dos anos do período estudado, com destaque para o ano de 2009 que registrou mais do que o dobro de ocorrências que 2006, segundo colocado em número de ocorrências,e dezoito vezes mais ocorrências que o ano de 2007, que registrou o menor número (Tabela 3)

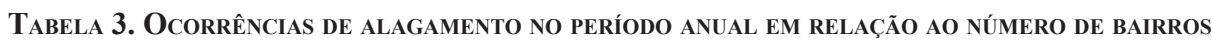
ATINGIDOS.

Table 3. Flooding occurrences in the anNual Period in Relation to the Number of afFected NEIGHBORHOODS.

\begin{tabular}{l|l|l}
\hline Ano & Número de Ocorrências & \multicolumn{2}{l}{ Número de Bairros Atingidos } \\
\hline 2006 & 357 & 74 \\
\hline 2007 & 43 & 25 \\
\hline 2008 & 231 & 61 \\
\hline 2009 & 797 & 83 \\
\hline
\end{tabular}

Fonte: Defesa Civil de Salvador (2010). Source: Defesa Civil de Salvador (2010).

A distribuição mensal das ocorrências de alagamento também varia, mas a concentração ocorre principalmente entre Março e Junho (Tabela 4), sendo que em 2006 a concentração ocorre entre Abril a Junho. Em que 2007 foi registrado o menor percentual de ocorrências, sendo que o referido ano apresentou as menores médias mensais no período mais úmido.
Em 2008 houve um aumento considerável de ocorrências em relação ao ano anterior, o que acompanhou as médias pluviométricas que foram maiores. Por último, o ano de 2009, que apresentou mais ocorrências do os três anos anteriores juntos e afetou consequentemente, o maior número de bairros do período.

\section{TABela 4. Distribuição Mensal das ocorrênCias de alagamento.}

Table 4. Monthly distribution of Flooding OF EVEnTs.

\begin{tabular}{l|l|l|l|l} 
Mês & $\mathbf{2 0 0 6}$ & $\mathbf{2 0 0 7}$ & $\mathbf{2 0 0 8}$ & $\mathbf{2 0 0 9}$ \\
\hline Janeiro & 5 & 2 & 0 & 0 \\
\hline Fevereiro & 1 & 19 & 12 & 3 \\
\hline Março & 4 & 3 & 138 & 4 \\
\hline Abril & 103 & 8 & 29 & 21 \\
\hline Maio & 147 & 4 & 31 & 606 \\
\hline Junho & 25 & 2 & 6 & 100 \\
\hline Julho & 9 & 2 & 5 & 15 \\
\hline Agosto & 2 & 0 & 1 & 14 \\
\hline Setembro & 0 & 2 & 0 & 9 \\
\hline Outubro & 30 & 1 & 0 & 23 \\
\hline Novembro & 31 & 0 & 9 & 2 \\
\hline Dezembro & 0 & 0 & 0 & 0 \\
\hline
\end{tabular}

Fonte: Defesa Civil de Salvador (2010). Source: Defesa Civil de Salvador (2010). 
Um percentual maior que $90 \%$ das ocorrências foram registradas nos meses de Maio (média de todas as estações de $706,5 \mathrm{~mm}$ ) e Junho o que agravou o impacto pluvial na rede de drenagem urbana. Fazendo-se a distribuição mensal de todas as ocorrências de alagamentos no período, percebe-se a relação direta com a precipitação pluvial, uma vez que, os meses em que se concentraram o maior número de ocorrências foram também os meses mais úmidos (Fig. 3).

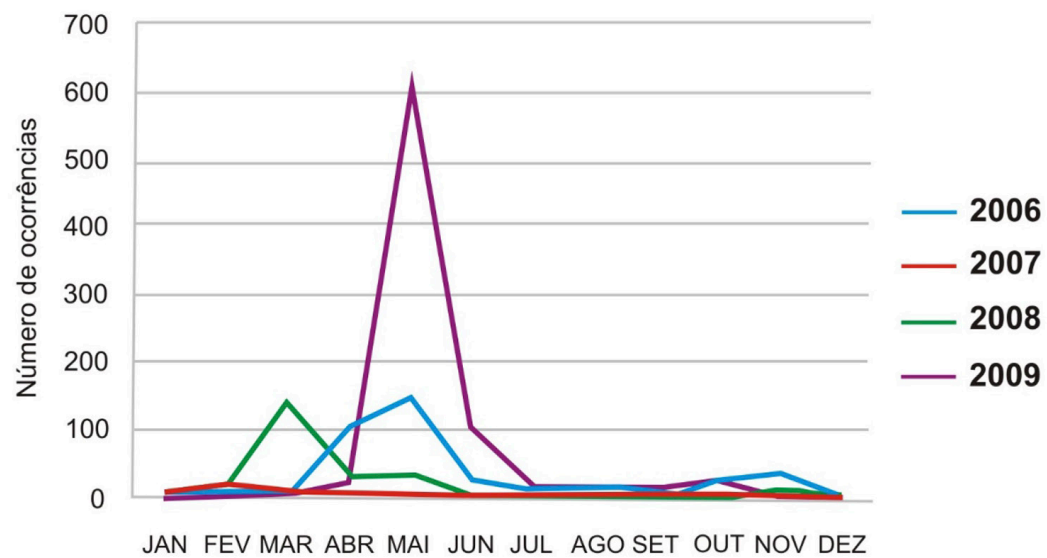

Fig. 3. Distribuição mensal das ocorrências de alagamento registradas.

Fig. 3. Monthly distribution of flooding occurrences recorded.

Ampliando-se o universo de análise, analisando as ocorrências em relação à alguns bairros mais afetados, pode-se ver que o aumento ou diminuição das ocorrências acompanhou as características de intensidade da precipitação pluvial, sendo os bairros mais críticos os de Boca do Rio, Bairro da Paz e São Cristovão (Fig. 4)

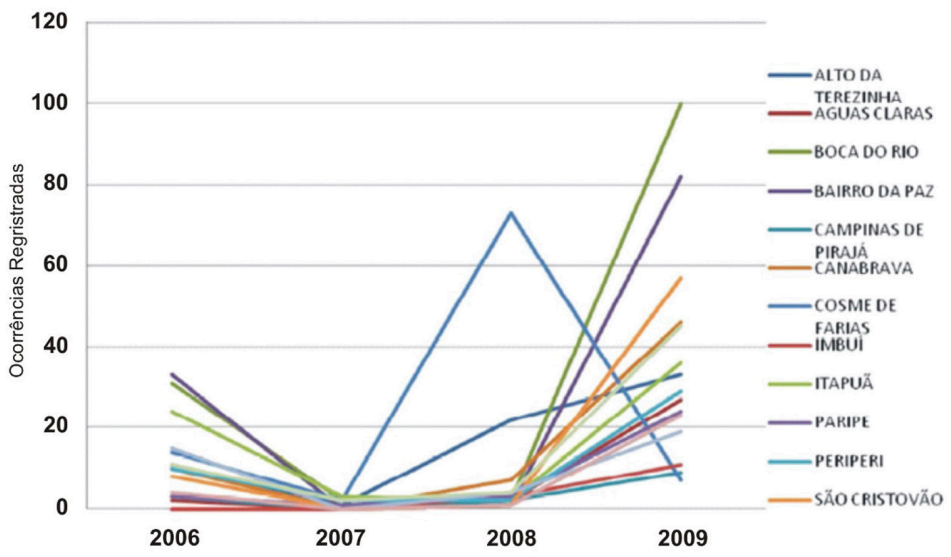

Fig. 4. Evolução das ocorrências de alagamento nos bairros mais afetados da cidade de Salvador no período de 2006 a 2009.

Fig. 4. Evolution of flooding events in the most affected districts of the city of Salvador from 2006 to 2009. 
Ainda analisando a figura 4, percebe-se que os eventos de alagamento comportaramse de maneira curiosa no bairro Cosme de Farias, aumentando as ocorrências de maneira abrupta em 2008 e registrando no ano seguinte menos de 10 ocorrências. Isto gerou uma amplitude de quase 60 registros, podendo-se perceber que neste caso, as ocorrências não resultam apenas da precipitação pluvial. Investigando os registros observou-se que mais de $60 \%$ dos alagamentos ocorridos no bairro em 2008 se concentraram em duas ruas localizadas próximas a uma escadaria drenante. Essa estrutura concentra o escoamento da região e sua obstrução associada a um grande fluxo foi responsável pelo grande número de ocorrências neste ponto, revelando a vulnerabilidade dessa região caso não haja manutenção por parte da prefeitura.

\section{Análise da distribuição espacial das ocorrências de alagamento associadas à precipitação}

A análise da espacialização dos eventos pluviométricos foi possível através da correlação com as ocorrências de pontos de alagamento fornecidas pela Defesa Civil de Salvador e buscou-se evidenciar para cada mês em estudo as áreas mais criticas, isto é, aquelas mais vulneráveis aos impactos pluviais. Essa análise foi realizada ano a ano, considerando os meses de maior precipitação.

\section{O Ano de 2006}

Considerando o ano de 2006, ressalta-se que os meses de Janeiro e Fevereiro, assim como os meses de Julho, Agosto, Setembro e Dezembro mantém as características de déficit pluviométrico e, nessa perspectiva, a análise de densidade de pontos de Kernel não revelou qualquer relação entre as ocorrências de alagamento registradas nesses meses e a drenagem. Assim, a seguir serão analisados apenas os meses em que o total pluviométrico foi expressivo e/ ou meses em que foram comprovadas relações entre ocorrências de alagamento e problemas relacionados à drenagem pluvial (Fig. 5).

O mês de Março apresenta a interpolação de maior valor precipitado no primeiro trimestre e, conforme verificado no mapa de espacialização de chuvas, a interpolação gerou intervalos de máximos de precipitação de $300 \mathrm{~mm}$ mensal e a análise de densidade não identificou relação entre os poucos pontos de alagamentos na cidade.

O mês de Abril registrou um alto intervalo de interpolação que variou de 500 a $700 \mathrm{~mm}$ e, ao ser comparado com o mapa de densidade de pontos de alagamento, observa-se pelo fatiamento ocorrências que variaram de 5 a 10 registros, localizando-se no Bairro da Paz, Boca do Rio e uma área maior abrangendo os bairros de Nazaré, Engenho Velho de Brotas e Cosme de Farias.

$\mathrm{Na}$ análise do mês de Maio, que registrou $41,18 \%$ das ocorrências de todo o ano, as áreas afetadas estão situadas no bairro de Fazenda Coutos e em Praia Grande, Alto da Terezinha e Plataforma, bairros pertencentes à região administrativa denominada Subúrbio Ferroviário. A interpolação dos dados pluviométricos mostrou os intervalos de mínimos de $300 \mathrm{~mm}$ e máximos de $900 \mathrm{~mm}$, evidenciando a alta média de precipitação mensal.

A distribuição de ocorrências pelo estimador de densidade de kernel mostrou um intervalo de 5 a 10 faixas de registro de alagamento próximos, demonstrando a existência de locais críticos de drenagem insuficiente, sem manutenção ou obstruída. $\mathrm{Na}$ região mais próxima ao extremo sul da cidade, os bairros que registraram ocorrências foram o Engenho Velho de Brotas, Brotas, Cosme de Farias e Engenho Velho da Federação. Na porção central da cidade destacaram-se os bairros de São Marcos, Sussuarana, Canabrava e Mata Escura. Também apresentaram alagamento as regiões circunvizinhas Fazenda Grande 
do Retiro, Lobato, Pirajá, Plataforma, Águas Claras e Valéria. No extremo oeste, região em expansão urbana, apresentaram fortes ocorrências os bairros de São Cristovão, Mussurunga I, Nova Brasília e Itapuã.
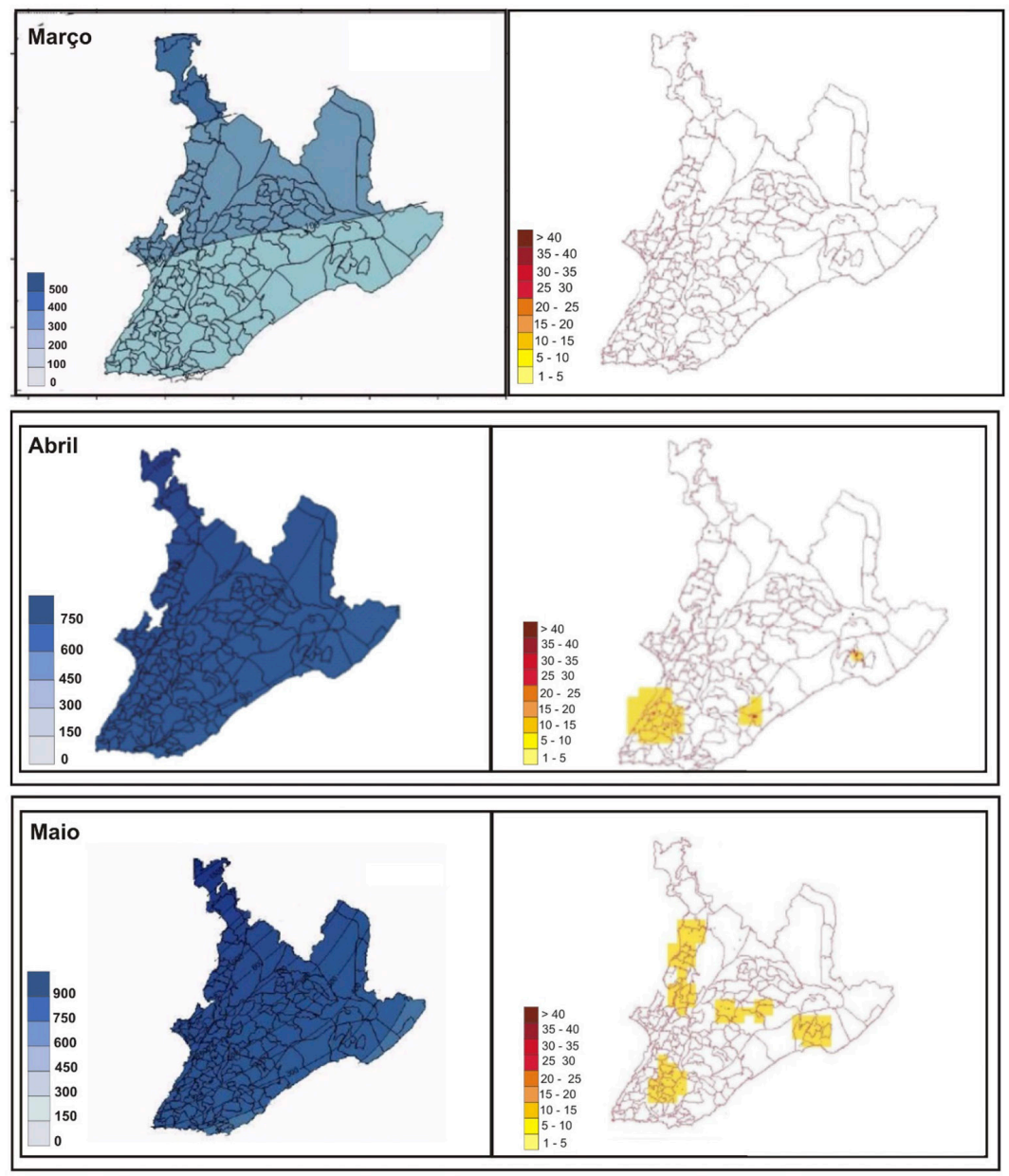

Fig. 5. Espacialização de chuvas versus ocorrências de alagamento nos meses de Março, Abril e Maio de 2006.

Fig. 5. Spatial distribution of rainfall versus occurrences of flooding in the months of March, April and May 2006.

Continuando a análise para o ano de 2006 (Fig. 6), constatou-se que Junho, que representou somente $7 \%$ de todas ocorrências anuais, teve uma configuração interessante, cujo mapa de interpolação do mês com intervalos de precipitação mínima de $200 \mathrm{~mm}$ e máxima de 600 $\mathrm{mm}$, comprovou a umidade do período, característica já discutida da cidade. Porém, a análise da distribuição das ocorrências, mostrou que neste mês a área de vulnerabilidade se concentrou no bairro Boca do Rio, que apresentou 23 ocorrências do total de 25 do mês, com vários pontos concentrados em apenas três ruas, o que demonstra a necessidade da intervenção do poder publico nestes pontos específicos. 
No mês de Outubro houve um total de 30 ocorrências de alagamento, o que representa $8,4 \%$ do total anual com concentração de ocorrências nos bairros de Matatu, Engenho Velho de Brotas e Cidade Nova, área que está dentro do maior intervalo de interpolação para as chuvas do mês entre $200 \mathrm{~mm}$ e $450 \mathrm{~mm}$.

Em Novembro, houve um total de 31 ocorrências de alagamento que representou $8,7 \%$ do total anual, com concentração no bairro de Itapuã, quando as águas atingiram as ruas mais baixas, próximo à avenida de acesso ao aeroporto internacional " $2 \mathrm{de}$
Julho", além de alagamentos registrados em Alto do Coqueirinho e Nova Brasília de Itapuã. Outra área bastante afetada, com registro de 11 ocorrências, foi a região dos bairros de São Marcos e Tancredo Neves, com registro de alagamento total na rua São Jorge da Bela Vista. No mapa de interpolação, prevaleceu os intervalos de 175 a $400 \mathrm{~mm}$ mensais, número bastante inferior se comparado aos meses mais críticos, o que revela, uma vez mais, que as ocorrências se deram não por excesso de chuvas, mas por deficiência na manutenção da rede de drenagem.
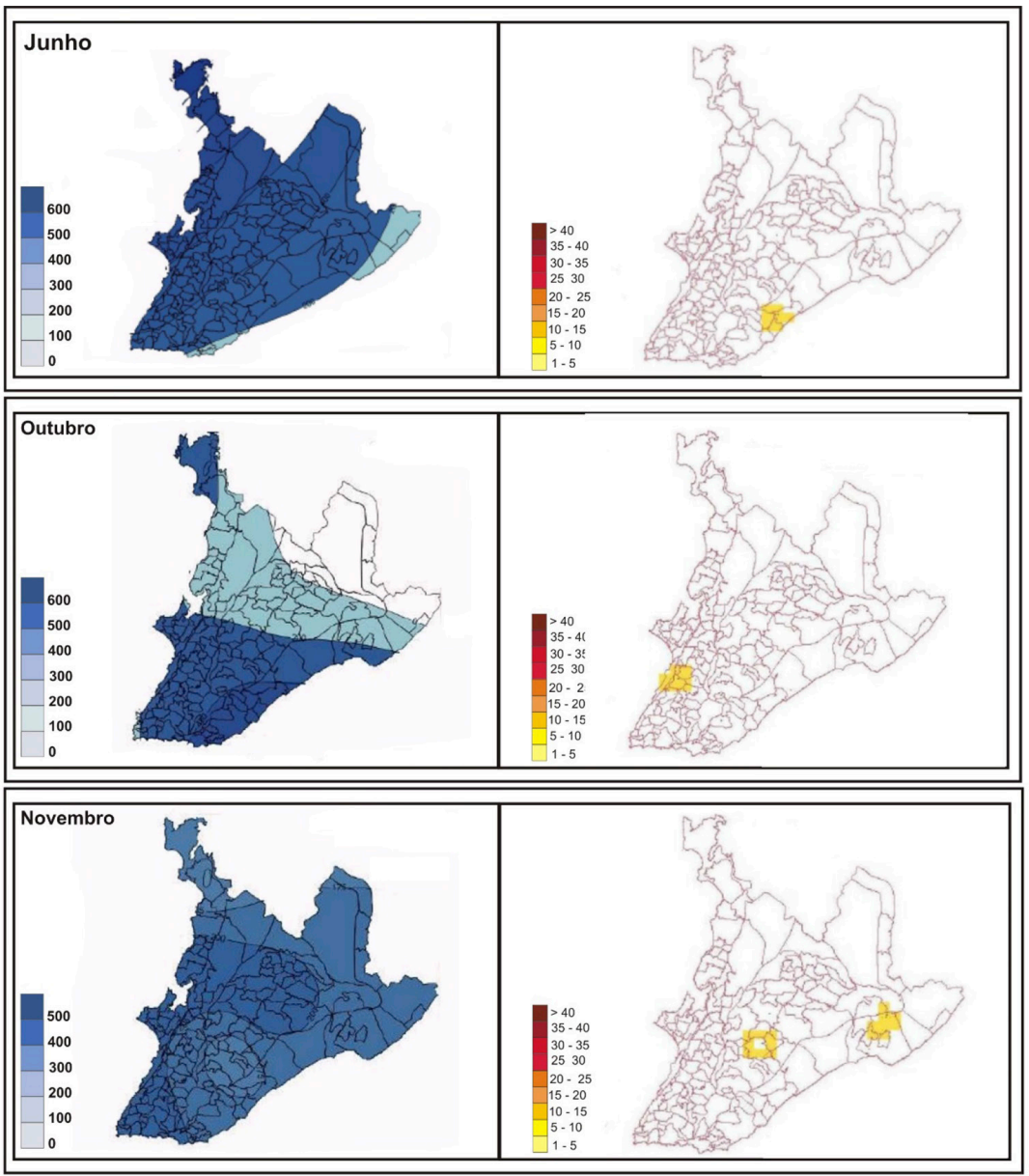

Fig. 6. Espacialização de chuvas versus ocorrências de alagamento nos meses de Junho, Outubro e Novembro de 2006.

Fig. 6. Spatial distribution of rainfall versus occurrences of flooding in the months of June, October and November 2006. 
O Ano de 2007

O ano de 2007, cujos meses representados foram Fevereiro e Maio (Fig. 7) apresentou precipitação mensal abaixo da média, variando de 0 a $200 \mathrm{~mm}$, como pode ser comprovado pela interpolação obtida para o mês de Fevereiro, sendo este mês escolhido por ter sido o único a apresentar ocorrências consideráveis e concentradas de alagamento.

Durante todo o ano de 2007, foram registradas 43 ocorrências pela defesa civil, sendo que deste total $44,19 \%$ dos registros são referentes ao mês de Fevereiro, com destaque para o bairro Cidade Nova e, como pode ser observado no mapa de densidade, sua faixa revelou-se mais como um caso pontual, uma vez que foram analisados os registros da defesa civil para este mês e observou-se que as ocorrências do referido bairro se concentraram na Rua Trasybulo Ferraz. No entanto, esta não se configurou como uma área critica de drenagem, uma vez que a concentração em uma única rua indica que esse evento no referido mês possa ter relação com obstrução das bocas de lobo por detritos ou lixo, pois não prevaleceu para os outros meses do ano.

Para o mês de Maio, que deteve a maior interpolação pluviométrica do ano, o mapa de densidade de riscos não indicou nenhum intervalo de ocorrências.
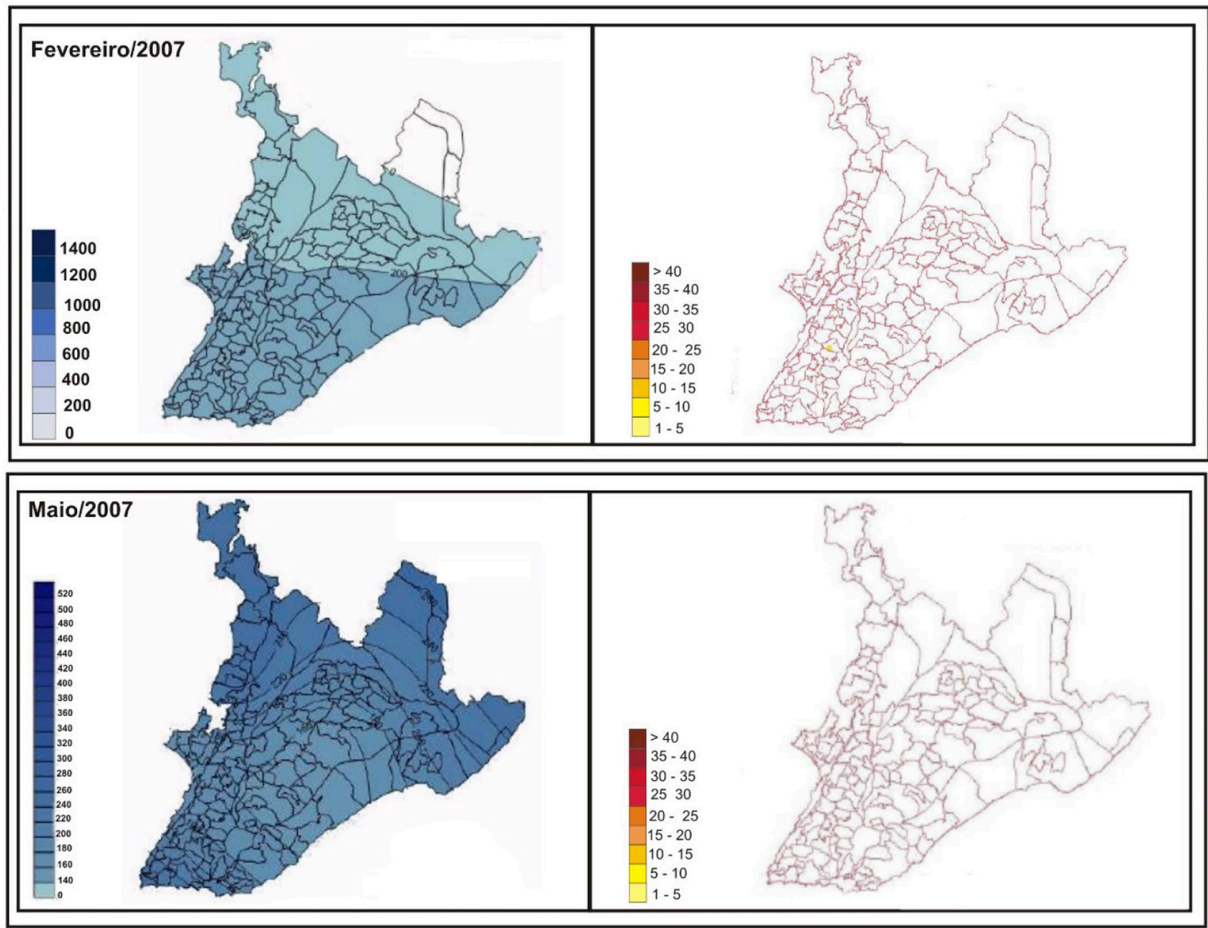

Fig. 7. Espacialização de chuvas versus ocorrências de alagamento nos meses de Fevereiro e Maio de 2007

Fig. 7. Spatial distribution of rainfall versus occurrences of flooding in the months of February and May 2007. 
O Ano de 2008

O ano de 2008 apresentou um total de 231 ocorrências de alagamentos distribuídas pela cidade e, ao analisar o mês de março de 2008 foram identificadas áreas de riscos pelo estimador de densidade de Kernel. Assim a análise se dará de maneira sucinta, pois este mês foi o único que apresentou correlação espacial entre suas ocorrências de alagamentos (Fig. 8).

A espacialização da precipitação para Março indicou precipitação abaixo da média mensal, com intervalos mínimos e máximos de 0 a $100 \mathrm{~mm}$, respectivamente. Apesar da baixa precipitação em relação aos demais meses analisados, o mês de Março de 2008 concentrou $59,7 \%$ de todas as ocorrências do ano. A análise de densidade revelou áreas criticas entre os bairros Alto da Terezinha, Plataforma, Rio Sena e Praia Grande e a área que compõem os bairros de Águas Claras e Cajazeiras.

A área com maior destaque está localizada na região dos bairros de Cosme de Farias, Engenho Velho de Brotas, Brotas, Matatu de Brotas, Escada e Vila Laura. O bairro de Cosme de Farias apresentou um total de 62 ocorrências concentradas nas ruas Antonio Viana, Edson Saldanha e Avenida Saldanha, ressaltando-se que nas proximidades há uma rede de macrodrenagem que apresentou obstrução, comprometendo toda a área; após a intervenção do poder público a região não apresentou ocorrências tão concentradas e intensas nos meses posteriores.

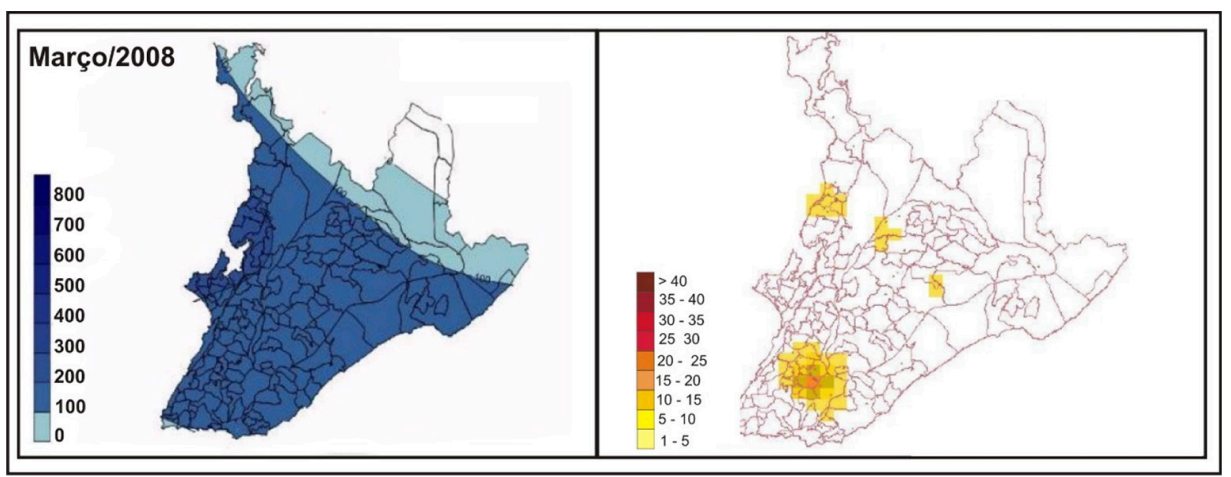

Fig. 8. Espacialização de chuvas versus ocorrências de alagamento no mês de Março de 2008.

Fig. 8. Spatial distribution of rainfall versus occurrences of flooding events in March 2008.

O Ano de 2009

No ano de 2009, um ano com pluviosidade acima da média, apresentando um total de 797 ocorrências, a maior quantidade da série histórica estudada, analisaremos os meses mais críticos (Fig. 9).

O mês de Abril apresentou uma espacialização da precipitação com valores mínimos e máximos de 300 a $500 \mathrm{~mm}$, respectivamente, apresentando uma média mensal de aproximadamente $383 \mathrm{~mm}$ em todas as estações analisadas.

As ocorrências no mês mantiveram-se baixas, sendo um total de 21, representando $2,6 \%$ do total anual. Foi registrada apenas uma ocorrência em cada um dos seguintes bairros: Saboeiro, Mussurunga I, Nordeste de Amaralina, Alto do Coqueirinho, Engenho da Federação, Alto da Terezinha, Paripe e Imbuí. Entretanto, em Ceasa foram registradas 5 ocorrências, concentrando- 
se na Rua Principal e na Rua Ferreira da Paz. Estes fatos comprovam os resultados obtidos na análise de densidade, pois com alagamentos afastados e pontuais em sua maioria, somente em Ceasa apresentou-se, coerentemente, uma faixa de 1 a 5 pontos de alagamentos.

O mês de Maio apresentou um intervalo mínimo e máximo de interpolação de 500 a $900 \mathrm{~mm}$, respectivamente, configurando-se como a maior média de todas as estações no período estudado com aproximadamente $706 \mathrm{~mm}$.

As ocorrências mensais também foram as mais altas de toda a série estudada, sendo 606 registros, caracterizando $76,04 \%$ do total do ano de 2009. Destes registros, destacam-se os bairros de Águas Claras, com 22 ocorrências; Alto da Terezinha, com 27 ocorrências; Bairro da Paz, com 72 ocorrências; Boca do Rio, com 84 ocorrências; Canabrava, com 43 ocorrências; Itapuã, com 36 ocorrências; São Cristovão, com 54 ocorrências; e Tancredo Neves, com um total de 39 ocorrências.

As áreas mais críticas da cidade estão situadas em toda região nordeste do município, abrangendo os bairros de Paripe, Fazenda Coutos e Periperi. Nos subúrbios ferroviários, os destaques são os bairros de Praia Grande, Alto da Terezinha e Plataforma. Na região sul da cidade os bairros que registraram o maior número de ocorrências foram Engenho Velho de Brotas, Brotas, Cosme de Farias e Engenho Velho da Federação.

$\mathrm{Na}$ porção central apresentou eventos significativos os bairros de São Marcos, Sussuarana, Canabrava e Mata Escura. Também apresentaram alagamentos as regiões circunvizinhas como Fazenda Grande do Retiro, Lobato, Pirajá,
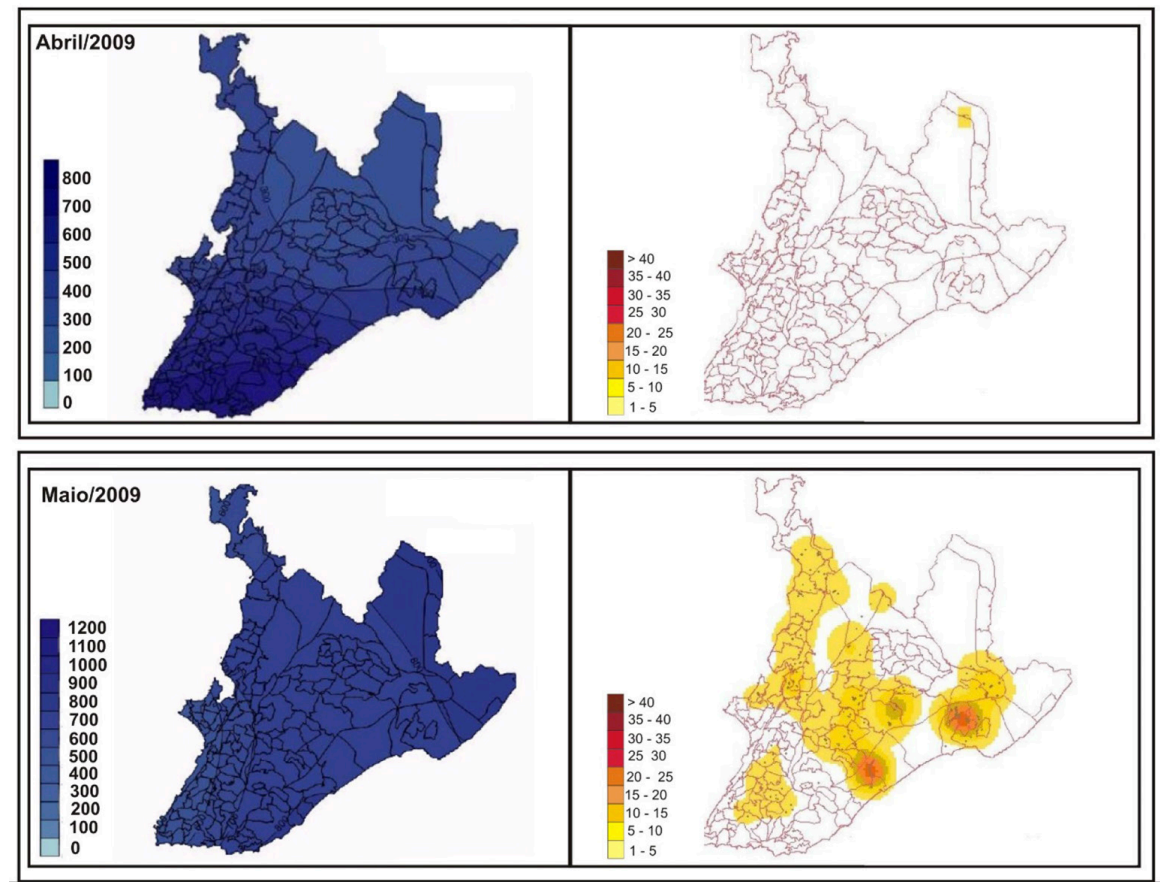

Fig. 9. Espacialização de chuvas versus ocorrências de alagamento nos meses de Abril e Maio de 2009.

Fig. 9. Spatial distribution of rainfall versus occurrences of flooding in the months of April and May 2009. 
Plataforma, Águas Claras e Valéria. No extremo oeste, região em alta taxa de expansão urbana, apresentaram fortes ocorrências os bairros de São Cristovão, Mussurunga I, Nova Brasília e mais ao litoral, Itapuã.

\section{DISCUSÃO E CONCLUSÕES}

$\mathrm{O}$ aumento de frequência e intensidade dos eventos climáticos extremos, especialmente nas áreas urbanas, têm promovido catástrofes, aumentado a vulnerabilidade a riscos e consequentemente, ampliado o debate sobre o tema e impulsionado a busca de soluções com vistas à adoção de medidas efetivas de prevenção e mitigação dos danos tanto no âmbito socioambiental quanto econômico.

Nesse contexto, o uso das geotecnologias vêm sendo apontado com uma das ferramentas mais eficazes para a proposição de soluções, tendo em vista a capacidade que possui essa tecnologia de agregar um grande volume de dados aliado à análise espacial, o que possibilita o cruzamento de informações e inclusive, em muitos casos, a inferência de respostas a partir da criação de cenários virtuais futuros.

Nesse contexto e considerando o caso específico deste estudo, a partir da utilização de um interpolador não exato como técnica empregada para a espacialização de chuvas, é importante ressaltar que a metodologia utilizada apresenta vantagens e desvantagens que deve ser consideradas.

No rol de vantagens quanto ao uso do método de curvatura mínima é importante salientar que a superfície estimada é independente da distribuição dos dados e da presença de ruído; a superfície estimada é a mais suave entre as geradas por outros algoritmos que ajustam superfícies de dados amostrados; a superfície é absolutamente fiel aos dados originais se houver apenas um valor amostrado por célula; há um menor número de formas estranhas, com exceção das bordas e interior de células sem amostragem; é capaz de estimar além dos valores máximo e mínimo dos dados amostrados.

Por outro lado, traz como desvantagens o fato de que uma superfície suave é gerada, quer realmente exista ou não; havendo dados próximos às bordas pode haver geração de depressões ou picos nas bordas do mapa; formas estranhas podem surgir no centro das células que não contém pontos amostrados e se um número insuficiente de interações for especificado.

Além disso, verificou-se que o método de curvatura mínima suaviza os contornos apresentando uma superfície suave e ainda produz curvas em lugar onde não existem dados, principalmente nas bordas.

A partir da espacialização dos dados, foi possível constatar que em todos os anos avaliados o mês que se revelou mais úmido foi o mês de Maio, embora tenha sido possível constatar precipitação superior à média também nos meses de Abril e Junho. Nesse contexto, a utilização do estimador de densidade de Kernel constituiu um método de simples aplicação para o estudo do comportamento das ocorrências de alagamento, com base no tamanho e distância entre fragmentos disponíveis para análise.

Os resultados obtidos através da interpolação dos dados pluviométricos e a análise de densidade de ocorrências de alagamento de Kernel quando analisados em conjunto apresentam algumas características importantes: a grande maioria de alagamentos ocorreram em anos de pluviosidade abundante (períodos úmidos); de modo geral, os episódios de alagamento são precedidos por períodos chuvosos, relativamente abundantes, nos 30 dias anteriores, mostrando a própria 
característica do regime pluviométrico anual, ou seja, a concentração sazonal da pluviosidade; na análise das densidades de ocorrências de todos os meses da série estudada, foram identificadas duas áreas criticas principais: Uma localizada na região de Boca do Rio, que registrou intervalos de 25 a 35 ocorrências de alagamento e o Bairro da Paz e contornos próximos com intervalos de 15 a 35 ocorrências.

Em geral, a problemática ambiental das áreas urbanas brasileiras resulta do crescimento demográfico acelerado associado às complicações relativas à questão habitacional, bem como da deficiência de infraestrutura básica, das desigualdades socioeconômicas e da conseqüente segregação espacial, fatores que repercutem com grande intensidade no ambiente natural.

Considerando os dados avaliados no contexto desta pesquisa e os resultados obtidos para o período em estudo (2006 a 2009), pôde-se constatar que, seguindo as tendências encontradas em estudos semelhantes, os impactos pluviais têm acompanhado o processo de expansão urbana e sua ocorrência vêm aumentando a partir da incorporação de novos espaços ocupados, sobretudo em áreas consideradas de risco, processo este que afeta sobretudo a população menos favorecida.

A análise espacial dos eventos extremos no âmbito desta pesquisa revelou a existência de áreas mais vulneráveis que outras no espaço urbano, áreas estas com problemas crônicos, cujos pontos críticos se encontram devidamente cadastrados pela defesa civil em função rotina do órgão. No entanto, essas áreas não vêm sendo priorizadas através de ações efetivas de planejamento e gestão dos riscos ambientais que dêem conta de mitigar ou sanar essas ocorrências. É importante ressaltar, porém que as informações coletadas pela defesa civil necessitam ser tratadas através de estudos aprofundados, com cruzamento de dados que utilizem, por exemplo, informações dos censos fornecidos pelo Instituto Brasileiro de Geografia e Estatística com vistas à formação de um banco de dados mais robusto onde sejam consideradas, inclusive, as modificações do escoamento superficial e das bacias hidrográficas da região, informações estas relevantes ao planejamento urbano da cidade.

Além disso, pode ser relevante, no futuro, a correlação dos resultados obtidos nesta pesquisa com os pontos da cidade de Salvador considerados críticos pelo serviço de limpeza urbana, através de um enfoque que relacione espacialmente os alagamentos causados pela obstrução do sistema de drenagem, bem como é essencial que se estude a o direcionamento do escoamento superficial da cidade associado ao grau de impermeabilização do solo e a relação desta impermeabilização com os pontos de alagamento da cidade, o que contribuirá para a busca de soluções para o planejamento e intervenção urbanos.

Por outro lado, a análise espacial das chuvas na área urbana tendo como objetivo a caracterização do clima urbano e a confirmação da existência de microclimas em Salvador, só será possível mediante a ampliação da série histórica das estações existentes na cidade e a instalação de uma rede ampla de observação da dinâmica atmosférica, com consequente construção de um banco de dados para modelagem em Sistemas de Informação Geográgica.

As constatações obtidas no decorrer deste trabalho permitem afirmar que a vulnerabilidade de Salvador a inundações decorre, principalmente da acumulação de deficiências no planejamento e gestão da cidade, aspectos que só poderão ser superadas a médio e longo prazo, embora demandem desde o presente momento uma série de ações efetivas tendo como suporte os estudos já realizados. 


\section{REFERÊNCIAS}

ALMEIDA, M. V., 2002. Estimativa da precipitação via radar para região metropolitana da cidade do Rio de Janeiro. Universidade Federal do Rio de Janeiro, Rio de Janeiro. Inédita.

ATKINSON, G. D., 1975. Forecaster's Guide to Tropical Meteorology. USAF, Technical Report 240, Garland.

AYOADE，J.O., 1986. Introdução à climatologia para os trópicos. Difel, São Paulo.

BARBOSA, F. de A. dos R., 2006. Medidas de proteção e controle de inundações urbanas na bacia do rio Mamanguape. Universidade Federal da Paraíba, João Pessoa. Inédita.

BECKER, P., 2006. Obtenção de informações para Plano Diretor de Drenagem Urbana utilizando um SIG. Universidade Federal de Santa Catarina, Florianópolis. Inédita.

BRANDÃO, A.M. de P.M., 2001. Clima Urbano e Enchentes na cidade do Rio de Janeiro. In: Guerra, A. J. T. \& Cunha, S. B. da (Eds.), Impactos Ambientais Urbanos no Brasil, Bertrand Brasil, Rio de Janeiro: 4752.

BRASIL. Ministério do Planejamento, Orçamento e Gestão. Ministério do Meio Ambiente, 2007 Instituto Brasileiro de Geografia e Estatística. Pesquisa de informações Básicas Municipais. Perfil dos Municípios Brasileiros. IBGE, Brasília.

CÂMARA, G. \& J. S. MEDEIROS, 1998. Princípios básicos em geoprocessamento. In: Assad, E. D. \& Sano, E. E. (Eds.), Sistemas de informações geográficas: aplicações na agricultura. Embrapa, Brasília: 3 -11.
CÂNDIDO, D. H., 2007 Inundações no município de Santa Bárbara d'Oeste, SP: condicionantes e impactos. Universidade de Campinas, Campinas. Inédita.

CHRISTOFIDIS, D., 2001. Olhares sobre a política de recursos hídricos no Brasil: o caso da Bacia do Rio São Francisco. Universidade de Brasília, Centro de Desenvolvimento Sustentável, Brasília. Inédita.

CUNHA, M. I. R., 2007. Aspectos socioeconômicos e ambientais das inundações no Brasil no período de 2003 a 2006. Universidade de Brasília, Brasília. Inédita.

DNMET. DEPARTAMENTO NACIONAL DE METEOROLOGIA, 1992. Normais Climatológicas: 1961-1970. Brasília.

GOMES, G. J. C., 2005. Análise temporal e espacial do risco de escorregamento em Ouro Preto - MG utilizando um Sistema de Informação Geográfica. Universidade de Ouro Preto, Ouro Preto. Inédita.

GONÇALVES, N. M. S., 2003. Impactos pluviais e desorganização do espaço urbano em Salvador. In: Monteiro, C. A. De F. \& Mendonça, F. (Eds.), Clima Urbano. Contexto, São Paulo.

GRILLO, R. C. \& W. C. BRINO, 1994. O impacto da precipitação pluvial na cidade de Rio Claro. Revista de Geografia de Rio Claro, 19(1): 39-60.

HERRMANN, M.L.P., 2001. Levantamento dos Desastres Naturais Causados pelas Adversidades Climáticas no Estado de Santa Catarina no Período 1980 a 2000. Imprensa Oficial do Estado de Santa Catarina, Florianópolis.

IBGE. INSTITUTO BRASILEIRO DE 
GEOGRAFIA E ESTATÍSTICA, 2000. Censo Demográfico 2000. Governo Federal. Ministério do Planejamento Orçamento e Gestão.

IPEA. INSTITUTO DE PESQUISA ECONÕMICA APLICADA (Org.), 2011. Mudanças Climáticas - Sociedade de Risco, Revista Desafios do Desenvolvimento, 8 (68).

JARDIM, C.H., 2012. "Médias"e "desvios" na análise geográficoclimatológica: o episódio de chuva concentrada do dia 23 de novembro de 2010 e o veranico de janeiro/ fevereiro de 2011 em Belo Horizonte - MG. Revista Geografias, 08 (2): 35-49.

LANDSBERG, H. E., 1981. The urban climate. Academic Press, New York.

LOURENÇO, R. W., 1998. Comparação entre métodos de interpolação para Sistemas de Informações Geográficas. Universidade Estadual Paulista, Rio Claro. Inédita.

MARCELINO, E. V., 2008. Desastres naturais e geotecnologias: conceitos básicos. INPE, Santa Maria.

MARENGO, J.A., 2009. Mudanças Climáticas, Condições meteorológicas extremas e eventos climáticos no Brasil. In: Fundação Brasileira para o Desenvolvime nto Sustentável (Org.), Mudanças Climáticas e eventos extremos no Brasil, Fundação Brasileira para o Desenvolvimento Sustentável, Rio de Janeiro.

MENDONÇA, F.A., 2004. Impactos socioambientais urbanos. Editora da Universidade Federal do Paraná, Curitiba.

MONTEIRO, C.A. de F., 1969. A frente polar atlântica e as chuvas de inverno na fachada suloriental do Brasil. Editora da USP, São Paulo.
MONTEIRO, C.A. de F., 1971. Análise rítmica em climatologia: problemas da atualidade climática em São Paulo e achegas para um programa de trabalho. Climatologia. São Paulo, 1.

MONTEIRO, C.A. de F., 1976. O clima e a organização do espaço no Estado de São Paulo: problemas e perspectivas. Instituto de Geografia da Universidade de São Paulo, São Paulo.

MONTEIRO, C.A.F., 1991. Clima e Excepcionalismo: conjecturas sobre o desempenho da atmosfera como fenômeno geográfico. Universidade Federal de Santa Catarina, Florianópolis.

MONTEIRO, C.A.F. \& MENDONÇA, F, 2003. Clima Urbano. São Paulo: Contexto.

NETO, E. A., 2006. Problemática da Drenagem em Salvador. Revista Veracidade, 1 (1): 1-11.

NETO, J. L. S., 1998. Clima e organização do espaço. Boletim de Geografia de Maringá, 16 (1): 119-131.

NETO, J. L. S., 2008. Da climatologia geográfica à geografia do clima: gênese, paradigmas e aplicações clima como fenômeno geográfico, Revista da ANPEGE, 4: 1-18.

SANTOS, A. R. dos, 2001. Caracterização morfológica, hidrológica e ambiental da Bacia Hidrográfica do Rio Turvo Sujo, Micro-Região de Viçosa, MG. Universidade Federal de Viçosa, Viçosa. Inédita.

SARTORI, M. G. B., 1993. Distribuição das chuvas no Rio Grande do Sul e a variabilidade têmporoespacial no período de 1912-1984. In: V Simpósio de Geografia Física Aplicada, Anais: 275-280. Universidade de São Paulo, São Paulo. 
SAYDELLES, A. P., 2005. Estudo do campo térmico e das ilhas de calor em Santa Maria - RS. Universidade Federal de Santa Maria, Santa Maria. Inédita.

\section{SUPERINTENDÊNCIA DE ESTUDOS} ECONÔMICOS E SOCIAIS DA BAHIA,

2000. www.sei.ba.gov.br.

SELLERS, A. H. \& ROBINSON, P.J., 1986. Contemporany climatology. Longman Group Limited, New York.
TUCCI, C. E. M., 2002. Gerenciamento da Drenagem Urbana, Revista Brasileira de Recursos Hídricos, 7: 5-27.

ZANELLA, M.E., 2007. Impactos pluviais no bairro Cajuru - Curitiba - PR. MercatorRevista de Geografia da UFC, 06 (11): $93-$ 105.

ZAVATINI, J.A., 2002. O tempo e o espaço nos estudos do ritmo do clima no Brasil. Revista de Geografia de Rio Claro, 27 (3): 101-131. 